\title{
Una experiencia centrípeta: construcción de la autoría, modernidad y espiritualismo en Hacia el Oriente, de Inés Echeverría Bello*
}

\author{
Lorena Amaro Castro \\ Instituto de Estética, Pontificia Universidad Católica de Chile \\ lamaro@uc.cl
}

\begin{abstract}
Es posible detectar en los últimos años y en el marco de los estudios culturales y estético-literarios, un creciente interés por la experiencia liminar del viaje, vinculado con la postmodernidad, la globalización, el descentramiento y la fragmentación de la experiencia. El siguiente artículo aborda, en un sentido inverso, la experiencia del viaje como negación de la alteridad, en los ojos de la escritora chilena Inés Echeverría Bello (Iris), quien en Hacia el Oriente (1905/1917) recorre los lugares santos buscando encontrar no solo los paisajes e historias bíblicas (que reescribe), sino también afirmando un modo de espiritualidad, ya antes analizada literariamente por Bernardo Subercaseaux (2001). Esta espiritualidad se encuentra en conflicto con los rasgos modernizadores que la autora observa a lo largo de su viaje. El análisis a continuación aborda el peregrinaje religioso de Echeverría en relación con el contexto de producción de la autora y la relación entre género, religiosidad y escritura, en un espacio-tiempo intervenido por los valores y transformaciones propias de la modernización.
\end{abstract}

Palabras clave: Peregrinaciones, literatura de viaje, literatura de mujeres, autoría, identidad.

In recent years, it is possible to detect increasing interest for the consideration of the experience of travelling as a threshold, both in cultural studies, and literary-aesthetic studies. In this sense, travelling is related to postmodernity, globalization, decentering, and fragmentation of experience. Opposed to this view, the following article addresses the experience of travelling as denial of otherness, in the eyes of female Chilean Inés Echeverría Bello (Iris). In her book/travelling diary Hacia el Oriente (1905/1917) she visits the Holy Land searching for biblical landscapes and stories, which she rewrites in her text, but she also affirms a mode of spirituality which has been previously analyzed from a literary view by Bernardo Subercaseaux $(1998 ; 2001)$. This spirituality seems to be conflicted with the modernizing features that the author finds in the places where she travels. The following analysis tackles Echeverría's religious pilgrimage in relation to the production context of the author, and the connection between gender, religiousness and writing in a space and time which are intervened by values and transformation derived from modernization.

Keywords: Pilgrimage, Travel Literature, Women Literature, Authorship, Identity.

Recibido: 22 de abril de 2013

Aceptado: 27 de junio de 2013

\footnotetext{
* El siguiente artículo es producto de la investigación "Espiritualidad y mirada viajera de tres peregrinas chilenas: Amalia Errázuriz, Inés Echeverría y Violeta Quevedo", Concurso Fe y Cultura 2011 (IX Versión), Pontificia Universidad Católica de Chile.
} 
Hacia 1900, en Chile era usual que los jóvenes de élite viajaran en "gira de estudios" a Europa. Cruzaban el Atlántico con ánimo cosmopolita y afán imitativo, en busca, escribe el historiador Gabriel Salazar, de una dorada "postal parisina" (Salazar y Pinto 18; 48-49). De allí muchos regresaban transformados en mundanos liberales. En palabras de otro historiador, Manuel Vicuña, "en el imaginario de la época París representaba a un tiempo a la Babilonia contemporánea, fértil vivero del vicio y la impiedad, y a la metrópolis moderna por antonomasia, encarnación consumada de la cultura y de la civilización reverencialmente admirada por tantos patricios chilenos" (Vicuña 105-106).

Las oportunidades para los y las jóvenes que viajaban no eran las mismas. El grand tour ensanchaba las experiencias artísticas y culturales de los oligarcas chilenos, llegando a ser más valorado incluso que los estudios universitarios, como plantea Gabriel Salazar. Pero en tanto los jóvenes encontraban a su regreso importantes cargos políticos y comerciales que ocupar, las mujeres volvían a una vida doméstica aún bastante provinciana. Solo unas pocas mantenían tertulias culturales y sacaban frutos de su experiencia por medio de la escritura y la publicación de sus textos, ya que su destino, a fines del siglo XIX, era seguir principalmente confinadas al espacio hogareño, en un período de tensiones políticas y decisivas disputas entre sectores liberales y ultramontanos. Asimismo, muchas de ellas, a pesar de haber tenido en algunos casos contacto con sociedades más liberales, como la francesa, eran las principales defensoras de la Iglesia, amenazada por los vástagos viajeros que apoyaban la progresiva secularización del Estado. Es paradigmático que, bajo el gobierno de Domingo Santa María, en 1883 , un grupo de doscientas mujeres pertenecientes a la élite protestaran por las reformas institucionales que deseaba impulsar el Presidente, en lo referente a las regulaciones de la vida civil (matrimonios, nacimientos y defunciones) y, en general, las relaciones entre Iglesia y Estado. Los sectores más conservadores exigían que se respetaran sus convicciones y sobre todo las mujeres procuraron sostener la identidad católica a través de la acción caritativa, que sus maridos financiaban. Es en este contexto histórico que destaco una particular forma de repliegue espiritual: el viaje de peregrinación y la experiencia de la escritura devota, en oposición a la disolvente, centrífuga gira de estudios europea.

Entre fines del siglo XIX y la primera mitad del XX, hay al menos cuatro testimonios de viajes de tipo religioso en Chile. Solo uno de ellos fue escrito por un varón: Cartas de Jerusalén (1897), de Carlos Walker Martínez (18421905), político conservador. Los demás son de autoría femenina: Ios diarios de Amalia Subercaseaux (1860-1930), Mis días de peregrinación en Oriente, escritos durante sus dos viajes a Tierra Santa, en 1893 y 1894, respectivamente, y que fueron publicados sin fecha; luego, el libro al que me referiré en estas páginas, Hacia el Oriente, de Inés Echeverría Bello (1869-1949), publicado anónimamente en 1905 y solo doce años más tarde, en 1917, con el nombre de la autora, quien cuenta las dos peregrinaciones que realizó a Palestina, en 1900 y 1901; finalmente, El ángel del peregrino, de una sobrina de Amalia, Rita Salas Subercaseaux (1882-1965), de seudónimo Violeta Quevedo, quien relató su peregrinación por los lugares santos en Europa en El ángel del peregrino (1935). 
Nada más opuesto al Grand Tour mundano en que los jóvenes chilenos se iniciaban en la vida de alta sociedad y adquirían costumbres refinadas, que el viaje de peregrinación como es entendido por el catolicismo, fe a la que adscriben los cuatro autores mencionados. La peregrinación religiosa no es de su patrimonio exclusivo, pero sí adquiere un significado trascendental, profundamente vinculado con la doctrina religiosa. La peregrinación es comprendida como camino cristiano, "proceso de conversión, ansia de intimidad con Dios y súplica confiada en sus necesidades materiales", como la define el Pontificio Consejo de la Pastoral para los Migrantes e Itinerantes (párr. 2). Constituye la materialización del símbolo cristiano que es la vida como camino y como forma de extranjería (xeniteia), desde la peregrinación adámica, abrahámica o mosaica hasta el camino que anduviera Cristo, quien muy tempranamente vive la experiencia del éxodo y también la de la peregrinación religiosa, en compañía de María y José hasta el templo de Sión, como relata el Evangelio (ibíd. párr. 21). Pero no es solo el destino del viaje, hacia los lugares santos, el que hace el viaje del peregrino, sino que también una experiencia fundamental: "el alejamiento del tumulto de las cosas y de los acontecimientos" (ibíd. párr. 22), alejamiento que en las peregrinaciones que analizaremos era una difícil realización.

Quizás la única, entre todos los mencionados, que procura fijar su atención exclusivamente en los aspectos espirituales del viaje sea Amalia Errázuriz, quien también escribiría sobre su estadía en Roma y el Vaticano como esposa del diplomático Ramón Subercaseaux ${ }^{1}$ y llevaría adelante una serie de obras de caridad. Ella pormenoriza los incidentes del viaje vinculados con la devoción y sobre todo con el horario y el régimen de oración y reflexión que llevaban a bordo del Notre Dame de Salut, barco que en Navidad llevaba, según el testimonio de Carlos Walker Martínez -quien no viajó con ellos y que encontró principalmente la acogida franciscana que era tan importante por esos años en Jerusalén-, a un grupo de cerca de 400 personas a visitar Jerusalén, Belén y Nazareth, entre otros destinos ${ }^{2}$. La evolución de los transportes y las comunicaciones hacía mucho más fácil el viaje, hasta entonces de muy improbable realización. El naciente turismo finisecular es observado principalmente por Errázuriz y por Echeverría como una experiencia empobrecedora, como veremos a continuación. Pero no podían sustraerse de esos rasgos propios de la modernización, de manera de poder viajar. Tampoco podían sustraerse, por su educación (en la cultura francesa, principalmente), de la mirada eurocéntrica y colonialista de Europa sobre el Medio Oriente.

Particularmente interesante resulta el relato de Inés Echeverría, más conocida como "Iris" en el mundo literario chileno. Su texto es claramente más ambicioso que el de Errázuriz en su planteamiento literario: fusiona los diarios sostenidos en esas dos travesías en un formato memorialístico, en que por momentos se deja ver la arquitectura escondida del diario. Por otra parte, es interesante ver cómo, a diferencia del texto de Walker Martínez, publicado cuando este vivía sus últimos años y ya era autor de otras piezas

1 Cfr. Errázuriz, Amalia. Roma del alma. Roma: Impr. de la Unión Editrice, 1909-1910.

2 Cfr. Walker Martínez, Carlos. Cartas de Jerusalén. Santiago: Establecimiento Poligráfico Roma, 1897. 
dramáticas y poéticas, el de Iris es una opera prima, detalle que habla de la construcción de los sujetos autorales en ese momento cultural chileno, previo a la profesionalización del campo literario. Se trata además de una obra escrita antes de que en la vida de la autora se desatara el interés por la teosofía. En muchos textos ella hace profesión de fe y se refiere a "...la patria de mi alma: el catolicismo" (Echeverría, Memorias 29), pero, como es sabido, se irá acercando a lo largo de su vida a esas otras influencias, de las que ya da cuenta el interés con que se refiere en Hacia el Oriente a su paso por Egipto y el conocimiento de las primeras religiones monoteístas.

\section{Origen de Iris}

Los textos de peregrinaje a los que me he referido abarcan un período de aproximadamente cuarenta años, en que se produjeron transformaciones radicales en Chile, vinculadas a la modernización política y económica, también material y urbana. Entre estas transformaciones se cuenta la secularización de la vida política y el paulatino repliegue de la religión a la esfera de la vida privada. Pienso que esto explica, en gran medida, el hecho de que mujeres como Echeverría, Errázuriz o Salas se animaran a publicar, como primera obra, textos asociados a lo religioso, antes que otras formas de literatura. José Toribio Medina dedica en su libro sobre la escritura de las mujeres en Chile todo un capítulo a los textos de carácter devoto (oraciones, novenas y otros). Por otra parte, la producción de las autoras, proclive a las expresiones privadas, se inserta en un ámbito mucho más amplio, epocal y continental, en que críticas como Graciela Batticuore y Márgara Russoto han observado las múltiples facetas y dificultades de la construcción autoral femenina; su repliegue, por lo general, a "un escenario 'íntimo', autorreferencial, y desde una otredad semioculta y poco convencional" (Russotto 14), lo que hace de estos textos documentos particularmente interesantes.

De algún modo, con su escritura, estas autoras lograban canalizar sus pensamientos y comunicar sus experiencias, pero siempre desde un lugar donde la sociedad de su época esperaba que mantuvieran sus subjetividades. En el caso de Amalia Errázuriz, una de las fundadoras de la conservadora Liga de Damas Chilenas (1912), las obras posteriores siguieron estando inscritas en aquel ámbito, debido a que fue una activista religiosa. Su texto es, como se ha dicho, el que describe con más detalle la vida del peregrino (misas, oraciones, prédicas). Pero si miramos a Echeverría y Quevedo, ambas desarrollaron una carrera literaria ajena a las inquietudes religiosas que forjaron el camino de Amalia Errázuriz, sirviéndose hasta cierto punto de sus narraciones de peregrinaje como umbrales de acceso a la esfera cultural.

El que Iris publicara su primer libro de manera anónima también habla del difícil tramado de su autoría literaria. Es evidente que hay allí un temor, o al menos, una reserva ante la publicidad de su obra, aprensión que se desvaneció al poco tiempo. Ya en 1906 la revista Zig-Zag publicaba un extracto de este libro, indicando su nombre de mujer casada ("Inés Echeverría de Larraín") e incorporando, incluso, una fotografía suya. El texto, que había pasado ya por el escrutinio público (sobre todo de la buena sociedad de su época), había sido aprobado y podía ser ostentado como propio. Sin embargo, todavía no se configuraba el personaje "Iris", "la mensajera de los 
dioses" -como le gustaba explicar a ella misma el origen de ese nombre-, la autora respetada, polémica e incluso temida que se iría armando a sí misma a lo largo de los años.

Como deja ver la fecha de la primera publicación de Hacia el Oriente, Echeverría ingresó tardíamente en el mundo literario: contaba ya con 36 años, y solo muchos años más tarde abordaría el género novelesco. La propia autora se refiere a esta situación, reaccionando contra ella y enarbolando una bandera colectiva: "Hasta los treinta años yo fui una cosa, algo que habría podido llamarse sin desmedro un ser esclavo y hasta inconsciente. iY pensar que aquí hay mujeres que no pasan nunca de los treinta!" (cit. en Prado 44). Aun así, desarrolló su oficio en textos literarios y periodísticos que le valieron a veces el rechazo, pero también el reconocimiento de los lectores de su época y el que hoy sea considerada una precursora de las intelectuales y feministas chilenas. Es este un aspecto clave de su configuración autoral.

Críticos como Marcela Prado advierten que hay en Iris un doble discurso: por una parte, el pensamiento aristocrático, conservador, propio de su clase, y por otra, el progresismo que se vincula principalmente a esta condición femenina: "[es] precisamente, en su calidad de tal, que disiente de su clase y que su discurso se abre a nuevas ideas" (Prado 43). Pero lo hace "desde una ventana de casa colonial" (Subercaseaux 20), lo que lleva a que en sus textos se produzca un efecto que Bernardo Subercaseaux ha llamado polifónico, que él grafica analizando el relato "Hora de queda": "Lo que se postula como un espacio social desfasado, espacio que la voz autoral rechaza desde el punto de vista de la emancipación de la mujer -y también desde el punto de vista del cambio y la modernidad- se rescata finalmente como un espacio deseable desde el punto de vista de la actividad del espíritu, vida espiritual que en cierta medida el "afuera" amenaza y constriñe" (Subercaseaux 20).

Es así que la propia Iris resalta en sus páginas autobiográficas su estirpe, su parentesco con un personaje fundador como el jurista, poeta y gramático Andrés Bello, su filiación con la fundación política y social de la república: "Nací nieta, por carencia de madre. Arraigo en la misma Colonia y nazco en el riñón de la aristocracia entre las calles Catedral, Congreso y los Tribunales de Justicia" (Echeverría, Memorias 15). Al mismo tiempo, hace un gesto de corte radical, que la llevó a enfrentar los vacíos y la frialdad de muchos de los miembros de su clase social: "Yo solo nací a los treinta y ocho años, antes era un títere movido por hilos invisibles, producto de mi origen y educación. Ahora soy Iris" (cit. en Echeverría, Mónica 113). De hecho, el uso del seudónimo -con frecuencia parte del tramado autoral femenino que busca sortear la crítica social-coincide con el nacimiento de su hija menor, a quien dará este nombre, pero sobre todo, con la publicación en prensa de sus primeros textos.

En el diario/memoria Hacia el Oriente son muy visibles las tensiones propias de su discurso, toda vez que intenta modelar allí una escritura y una identidad modernas, que encubran y revelen, simultáneamente, los anhelos de arraigo de una identidad católica y europea, sólidamente forjada en la infancia, que incluso a veces retrotrae a un ethos colonial. Su texto oscila entre la mirada interior, la descripción periodística de lugares de difícil acceso para 
los lectores de aquella época y los diálogos mundanos, irónicos, sostenidos con los "pintorescos" viajeros que conoció en el peregrinaje. Esta diversidad la anuncia ella misma en su "Introducción" al relato, en términos similares a los que emplea Michel de Montaigne en sus famosos Ensayos: "Se extrañarán algunos de encontrar mezcladas en estas páginas tan diversas cosas, ya religiosas, ya artísticas, ya sociales, ya cómicas. Mi única respuesta será decirles que eso mismo soy yo" (Montaigne VI).

La presencia de la mirada interior a la que aludía antes, debe ser considerada a la luz de lo que Bernardo Subercaseaux ha descrito como una sensibilidad de época, que ha llamado "espiritualismo de vanguardia" y que se caracterizó por ser una estética de cuño arielista, antipositivista y antimaterialista: "Se trata de un discurso que percibe negativamente a la oligarquía del dinero, de la ostentación y la opulencia, un discurso que asume una perspectiva de regeneración, de rescate de los valores espirituales de la vieja y austera aristocracia de la sangre" (Subercaseaux 16). Como se verá, son esas experiencias las que rescatará Iris en esta primera obra que constituye, a mi modo de ver, una exploración o tanteo, un dispositivo que le permite hacerse un espacio en el campo literario. Por lo mismo, quizás, la escritora, que será conocida por su carácter polémico, escoge un tono a ratos irónico, pero no combativo, que dista mucho de trabajos suyos posteriores a 1910, que pueden tildarse de anticlericales y más críticos en lo que respecta a la posición de la mujer. Por el contrario, se produce en este texto un retorno de Iris al mundo de la infancia, vehiculizado por el encuentro con los paisajes bíblicos sobre los que leyó tempranamente. En este sentido, si bien la experiencia del viaje hoy es descrita como un descentramiento, en Iris opera un movimiento opuesto, un movimiento centrípeto. Mientras autores como Elena Altuna caracterizan la experiencia viajera como aquella que "altera radicalmente un estado de quietud, de certezas brindadas por un horizonte vital, para transformar al sujeto en el forastero, el extranjero, el inmigrante: el descentramiento es así la operación que se halla a la base de esa experiencia" (Altuna 9), en el caso del viaje de Iris encontramos, por el contrario, certidumbre, afianzamiento de una identidad religiosa y social, condenación de la alteridad. También se produce un retorno a la dulce región de la infancia. Escribe Walter Benjamin, para quien los viajes despertaban un anhelo que "no siempre me arrastraba a lo desconocido, sino que algunas veces me invitaba a volver a casa" (10), idea que me parece refleja, en parte, el periplo espiritual e intelectual de Iris en su peregrinación.

Con su viaje la autora revive momentos de la niñez, en que un personaje femenino, a quien llama simplemente "ella", posiblemente Dolores Echeverría, la tía que la crió bajo una estricta moral católica, le lee los textos sagrados. La mirada de Iris sobre el mundo oriental está velada, de este modo, por la pantalla bíblica, que en su caso funciona como texto matricial, como retorno a la inocencia y la infancia de los afectos.

\section{La maldición del tren}

En el mundo católico, la peregrinación constituye "una práctica religiosa un tanto periférica en relación con el culto litúrgico central en el seno de la Iglesia" (Quintana 1), pero con gran sentido evangelizador, razón última que 
alienta la peregrinación. Las viajeras de las que hablaré proyectan hasta cierto punto este ideario, todavía hoy presente en la Iglesia, explicitando en sus textos sus propósitos religiosos, que a veces no se condicen, como ya se ha dicho, con otros momentos de su relato, muy particularmente en el caso de Iris. Ella dirime la diferencia entre su viaje y el de los "turistas", describiendo la oposición entre unos y otros desde una idea de espiritualidad un poco vaga: "los que buscan el movimiento para sacudir la monotonía de su vida, que salen de su país tras de cosas nuevas o maravillosas que les hagan huir de sí mismos, ávidos de panoramas fantásticos, de costumbres extrañas que disipen el tedio en que se consume su vida ociosa; y los viajeros que buscan en los países que recorren la expansión de su propia vida interior, que no van a pedir a los horizontes aspectos que les diviertan sino emociones que alimenten su existencia íntima" (Echeverría, Hacia el Oriente VII-VIII).

En un artículo dedicado a Errázuriz y Echeverría, Verónica Ramírez explica cómo los viajeros de ese tiempo lograban concretar el difícil viaje a Jerusalén. Cada vez eran más quienes se dirigían a estos destinos, tanto con fines comerciales como políticos. Es en ese contexto que germina, a mediados del siglo XIX, la actividad turística. Aparecen grupos de peregrinación, coordinados por sacerdotes franceses, los que partían desde Marsella con una embarcación propia hacia el Medio Oriente. Pero no solo el transporte era europeo: también lo fue la mirada. La ideología que las viajeras portaban era eurocéntrica. Ramírez hace hincapié en la importancia de la expansión napoleónica sobre los territorios árabes y el consiguiente discurso colonialista (1).

Tanto la excursión de Amalia Errázuriz como la de Iris fueron dirigidas por sacerdotes asuncionistas, orden creada a mediados del siglo XIX y que tuvo una fuerte orientación a la evangelización y aprovechó la moderna tribuna que ofrecía la prensa; en Francia, estos sacerdotes, en particular el padre Vincent de Paul Bailly, habían intuido la importancia de las herramientas mediáticas de la vida moderna. Bailly fundó los periódicos Le Pélérin y La Croix, además de ser un conocido gestor de las excursiones religiosas. Tanto Errázuriz como Echeverría lo conocieron en sus travesías, realizadas por barco, tren y coche, y dejaron recuerdo de él en sus textos.

Una de las primeras tensiones presentes en el texto de Echeverría se produce entre la voz de la modernidad que habla en ella y, por otra parte, su condena a la vida moderna. En tanto describe entusiasta "las montañas escarpadas que corren presurosas como escenas de cinematógrafo por las ventanillas del wagón!" (Hacia el Oriente 407), critica las nacientes formas del turismo:

Esta llamada civilización, enemiga jurada de los poetas, de los artistas y de los peregrinos, no permite que hoy se llegue a Jerusalén por la ruta polvorosa que siguieron los patriarcas. Es una profanación, es una vulgaridad propia de la vida moderna, de nuestro pobre siglo el llegar a Jerusalén en un tren lleno de comerciantes turcos, de judíos, de turistas ociosos, mientras Godofredo de Bouillon entró con sus huestes, inclinando sus cascos como ante una 
meta divina, al divisar la Sion del rey David, la Jerusalén de Salomón y de los profetas (...) nosotros, desgraciados, que llegamos como un paquete de mercadería dentro de un vagón de ferrocarril! Si alguna vez en mi vida he maldecido el tren con todas las veras de mi alma, es ciertamente hoy que, venciendo mi amor propio, he tenido que arrodillarme en la banqueta y que llorar en público" (Hacia el Oriente 134-135).

Como muchas otras escritoras chilenas de la élite, Iris desarrolló una escritura que Bernardo Subercaseaux ha llamado "espiritualismo de vanguardia", en que la mirada transfigura la realidad "sometiendo siempre lo inferior a lo superior, al principio del alma que anima todo lo existente, desde los paisajes hasta las personas y el arte" (22). Desde esta perspectiva, es lógico que Iris haga un cuadro deprimente del tren, "hecho para los comerciantes que miden el tiempo por el dinero, para los que ignoran lo que es vivir por el alma (...) para los novedosos que tienen la fiebre del siglo, para los que no pueden llorar...". Más cercana por su formación a la cultura francesa y por nacimiento a la aristocracia colonial, Iris remata: "... el tren se ha hecho únicamente para los ingleses!" (Hacia el Oriente 135). Muchas páginas más adelante, cuando deba abandonar Palestina, la escritora volverá sobre esta jerarquización que ensalza las vivencias del alma por sobre las contingencias de la vida moderna, refiriéndose a sus experiencias en Jerusalén como "desgarraduras del denso velo en que estamos envueltos" (Hacia el Oriente 400), el velo cotidiano del materialismo.

Las formas que encontrará para evadir las visiones de lo que llama "realidad de la vida" son diversas. En parte, su escritura exalta permanentemente los presentimientos y las sensaciones de carácter místico, lo que lleva al sacerdote y crítico Emilio Väisse, de seudónimo Omer Emeth (en hebreo, "el que dice la verdad"), a impugnar lo que considera un exceso: "Iris desea definirse como escritora, pero no es más que un espíritu de pacotilla, mercadería de un bazar parisién, ambigua, con emotividades excesivas y variedades innumerables" (cit. en Echeverría, Mónica 127), apreciación nada amable que nos devuelve a la difícil configuración del sujeto autoral femenino, incluso si el tema tratado forma parte del mundo religioso, cada vez más relegado al espacio privado. Por otra parte, si hubiese que hacer una crítica hoy, es fácil observar en la autora un gesto común a muchos viajeros europeos por Oriente o por América Latina: ella deshistoriza su entorno, vacía la Palestina moderna de sus habitantes y proyecta en cada lugar que visita una misma escena: la escena bíblica, como explicaré a continuación.

\section{Viajeros que buscan libros}

Mary Louise Pratt plantea en su conocido ensayo Ojos imperiales, una idea bastante útil para la lectura de Iris, referida al modo en que los viajeros colonialistas describen los paisajes: "... el apartheid textual que separa al paisaje de la gente, los relatos de los habitantes de las descripciones de sus hábitats, responde a su propia lógica. El ojo europeo progresista presenta los hábitats de subsistencia como paisajes 'vacíos', dotados de sentido solo en función de un futuro capitalista y de sus posibilidades de producir 
un excedente comercializable" (125). En el caso de Iris, la visión que se encuentra detrás (o por delante, más bien) de este despojamiento, no es, por cierto, una visión del futuro, sino del pasado, propio de su cosmovisión judeocristiana: la visión bíblica.

Así como el escritor colonialista es un "pintor verbal" que construye paisajes altamente estetizados y genera una relación de dominio entre el que ve y el que es visto, proyectando el futuro colonial (Pratt 367-369), Iris lee en los paisajes algo ya creado, persistente, eterno. Antes de iniciar su viaje ella ya "sabe que no iba a encontrar ni el confort de la vida moderna, ni los espectáculos agradables, ni las creaciones del arte./Quería solo sentir la beIleza del Antiguo y Nuevo Testamento en los lugares en que se desenvolvió" (Hacia el Oriente VIII). Se vuelca, entonces, a configurar una visión del paisaje y los santuarios, muy descriptiva (hay que considerar que en esa época no todos tenían acceso a imágenes de estos lugares) y despoblada de vida humana. La Tierra Santa es, ante todo, un "escenario": "El país de Jesús, la tierra de los patriarcas, el escenario tranquilo en que se han desarrollado los acontecimientos misteriosos de la Biblia y del Evangelio tiene un prestigio que atrae a las almas" (Hacia el Oriente 131), escenario este en que se desarrollan "cuadros" ("No quiero describir el cuadro que se ofreció a mis ojos al entrar en la aldea [de Nazareth]", Hacia el Oriente 85). Es así como entiende lo que observa, como se puede ver en esta romántica descripción del Valle de Josafat, emplazamiento bíblico del Juicio Final: "Cuando se desciende a este valle de la muerte, se olvida el azul del cielo, se olvida el brillo del sol, se invoca la embriaguez de todas las melancolías y los desconsuelos de las más hondas tristezas" (Hacia el Oriente 172). Su lóbrega descripción corresponde con lo que debe ser el escenario para la reunión de los muertos.

Incluso una ciudad llena de movimiento como lo es y lo ha sido por siglos Jerusalén, es despoblada y transfigurada por la mirada de Iris: "En la paz de esta noche purísima, Jerusalén se me presentaba como una ciudad de ensueño; como una aparición quimérica, despojada de su miseria, de la hez humana que la puebla, envolviéndose en esa alegría de la vieja Sión que cantó el real profeta y revistiéndose de las pompas salomónicas en un esplendor triunfante que embargaba mi alma en emociones de soberana dulzura!" (Hacia el Oriente 143). En esta ciudad, a Iris le molesta la visión de musulmanes y judíos, a quienes describe la mayor parte del tiempo, como advierte Ramírez, desde una perspectiva eurocéntrica: como gentes bárbaras, que protagonizan incomprensibles escenas de barbarie.

Quiero recordar aquí una frase de Michel de Certeau, quien escribe, en La invención de lo cotidiano, que "los lectores son viajeros; circulan sobre tierras ajenas, como nómadas que cazan furtivamente a través de campos que no han escrito" (187). Pienso en una inversión de esta idea: de los lectores como viajeros, a los viajeros como lectores; Iris es una lectora proveniente de un espacio en la periferia del mundo europeo, civilizado, que ella admira. Como tal, emprende un viaje real, físico, para encontrarse con el lugar de sus lecturas. Así refuerza, por otra parte, su pertenencia a la "civilización", llegando a ser, en muchos pasajes, como destaca también Verónica Ramírez (v. Bibliografía), más europea que los europeos "ignorantes" que la acompañan, dejando entrever además su orgullo de clase y linaje. 
Iris relee en el paisaje al que le niega su historicidad, una historia asumida como sagrada en la niñez, e incluso va más allá, pues reescribe varios fragmentos de esa historia con sus propias palabras de escritora. Así lo hace, por ejemplo, cuando en Belén evoca la historia del rey David, entre otras historias bíblicas (Hacia el Oriente 192 y ss.). En este sentido, se podría decir que la aventura de Iris resulta quijotesca. Cito:

En estos paisajes de la Historia Santa, en que no hay piedra que no esté consagrada por una memoria, ni perfil de montaña que no sea el fondo de la decoración de un drama bíblico, la imaginación hace surgir venerables figuras de patriarcas, profetas de largas barbas y ojos inspirados, reyes, pitonisas y pastores... (Hacia el Oriente 84).

Esta relación entre lectura y escritura resulta de gran interés, toda vez que precisamente las tierras visitadas por Iris constituyen lo que el escritor francés Ernst Renan Ilamó el "quinto evangelio", en su Vida de Jesús (1863), lectura francesa a la que la políglota Iris seguramente pudo acceder en su juventud. "Un quinto Evangelio, lacerado, pero todavía legible, apareció a mis ojos" (Renan 40)3. Para hacer legible la Tierra Santa, tanto Iris como antes Amalia Errázuriz deciden vaciarla, de manera que aparezca "pura", sin las trizaduras de casi dos mil años de historia en que las disputas religiosas han dejado marcas por doquier. Solo vaciando el paisaje de la presencia humana de los contemporáneos es posible leer y también evocar, reescribir con la memoria, los hechos del Antiguo y el Nuevo Testamento que persiguen, ávidamente, estas lectoras y creyentes chilenas, como una manera de reconfigurar una identidad católica amenazada por las pugnas políticas y la modernización de las instituciones a fines del siglo XIX y comienzos del siglo $\mathrm{XX}$ en Chile $\mathrm{y}$, también, como una forma de probarse en tanto escritoras.

\section{Obras citadas}

Altuna, Elena. "Introducción: relaciones de viajes y viajeros coloniales por las Américas". En: Revista de Crítica Literaria Latinoamericana. Año XXX, N 60, Lima-Hannover, $2^{\circ}$ semestre de 2004, pp. 9-23. Impreso.

Benjamin, Walter. Infancia en Berlín hacia el 1900. Madrid: Abada Editores, 2011. Impreso.

Certeau, Michel de. La invención de lo cotidiano 1, Artes de hacer. México: Universidad Iberoamericana, 2000. Impreso.

Echeverría, Inés (Iris). Hacia el Oriente. Recuerdos de una peregrinación a la Tierra Santa. Santiago de Chile: Imprenta Cervantes, 1917. Impreso. "Hacia el Oriente", Revista Zig-Zag, 1905-1964. 59 v. N 60 (8 abr. 1906). Web. 12 oct. de 2012: http://www.memoriachilena.cl/temas/ documento_detalle.asp?id=MC0010828

3 Esta idea continúa vigente en la Iglesia. Es así, por ejemplo, que Benedicto XVI escribe: "Tierra Santa ha sido Ilamada un 'quinto Evangelio', porque aquí podemos ver, es más tocar la realidad de la historia que Dios ha realizado con los hombres (...) Sí, Dios ha entrado en esta tierra, ha actuado con nosotros en este mundo. Pero podemos decir más todavía: Tierra Santa, por su misma historia, puede ser considerada un microcosmos que resume en sí el esforzado camino de Dios con la humanidad" (579). 
Memorias de Iris. Santiago de Chile: Aguilar, 2005. Impreso.

Echeverría, Mónica. Agonía de una irreverente. Santiago de Chile: Sudamericana, 1997. Impreso.

Papa Benedicto XVI (Joseph Ratzinger). "Tierra Santa, un quinto Evangelio". Revista Humanitas. Año 14, No 55, invierno de 2009, p. 579. Impreso.

Montaigne, Michel de. Ensayos. Madrid: Cátedra, 1998, vol. I Impreso.

Prado, Marcela. "Inés Echeverría Bello (Iris) (1869-1949)". En: Patricia Pinto y Benjamín Rojas (Eds.). Escritoras chilenas. Novela y cuento. Santiago de Chile: Cuarto Propio, 1999, pp. 43-65. Impreso.

Pratt, Mary Louise. Ojos imperiales. Literatura de viajes y transculturación. México: FCE, 2010. Impreso.

Quintana, Gaspar. "El peregrino: su identidad y sus motivaciones". Tercer Congreso Americano de Rectores de Santuarios. Noviembre de 2002. Web. 12 oct. 2012 . http://www.google. $c l / u r l$ sa $=t \& r c t=j \& q=\& e s r c=s \& s$ ource $=$ web\&cd $=1 \&$ ved $=0$ CCOQFjAA\&url=http $\% 3 A \% 2 F \% 2 F w w w$. iglesia. cl\%2Fportal_recursos\%2Feclesial\%2Fpiedad_santuarios\%2Fel_peregrino. doc\&ei=30owUvWvKYaviALT24HgBQ\&usg=AFQjCNELgZOV3ppTiOvylzTMaoJyRpjFg\&sig2=GYZ9zX3s2jvkiaD-5mnMYg\&bvm=bv.52109249,d.cGE

Ramírez, Verónica. "Hegemonía occidental sobre el mundo. Los relatos de dos viajeras chilenas en Oriente". En: Revista Chilena de Literatura, Sección Miscelánea, abril de 2010. Web. 20 oct. de 2012: http://www. revistaliteratura.uchile.cl/index.php/RCL/article/viewFile/9131/9133

Renan, Ernest. Vida de Jesús. Madrid: Bergua, 1999. Impreso.

Russotto, Márgara (compilación y edición). La ansiedad autorial. Formación de la autoría femenina en América Latina: los textos autobiográficos. Caracas: Equinoccio, 2006. Impreso.

Salazar, Gabriel y Julio Pinto. Historia contemporánea de Chile. Niñez y juventud. Santiago: LOM Ediciones, 2002. Impreso.

Subercaseaux, Bernardo. "Estudio preliminar. Su obra y significación". En: Alma femenina y mujer moderna. Santiago: Cuarto Propio, 2001, pp. 11-32. Impreso.

Vicuña, Manuel. La belle époque chilena. Alta sociedad y mujeres de élite en el cambio de siglo. Santiago: Sudamericana, 2001. Impreso. 